\title{
Racial inequalities and perinatal health in the southeast region of Brazil
}

L.M. Silva ${ }^{1}$, R.A. Silva ${ }^{1}$, A.A.M. Silva ${ }^{1}$, H. Bettiol ${ }^{2}$ and M.A. Barbieri²

\author{
${ }^{1}$ Departamento de Saúde Pública, Universidade Federal do Maranhão, \\ São Luís, MA, Brasil \\ ${ }^{2}$ Departamento de Puericultura e Pediatria, \\ Faculdade de Medicina de Ribeirão Preto, Universidade de São Paulo, \\ Ribeirão Preto, SP, Brasil
}

\section{Correspondence \\ A.A.M. Silva \\ Departamento de Saúde Pública Universidade Federal do Maranhão Rua Barão de Itapary, 155 65070-020 São Luís, MA Brasil \\ Fax: +55-98-3232-1264 \\ E-mail: aasilva@elo.com.br}

Research supported by CNPq, FAPESP (No. 00/09508-7) and Fundação de Auxílio ao Ensino, Pesquisa e Assistência do HC, FMRP, USP.

Received August 30, 2006 Accepted June 4, 2007

\begin{abstract}
Few studies are available about racial inequalities in perinatal health in Brazil and little is known about whether the existing inequality is due to socioeconomic factors or to racial discrimination per se. Data regarding the Ribeirão Preto birth cohort, Brazil, whose mothers were interviewed from June 1, 1978 to May 31, 1979 were used to answer these questions. The perinatal factors were obtained from the birth questionnaire and the ethnic data were obtained from 2063 participants asked about self-reported skin color at early adulthood (23-25 years of age) in 2002/2004. Mothers of mulatto and black children had higher rates of low schooling ( $\leq 4$ years, 27.2 and 38.0\%) and lower family income ( $\leq 1$ minimum wage, 28.6 and 30.4\%). Mothers aged less than 20 years old predominated among mulattos (17.0\%) and blacks (14.0\%). Higher rates of low birth weight and smoking during pregnancy were observed among mulatto individuals (9.6 and 28.8\%). Preterm birth rate was higher among mulattos $(9.5 \%)$ and blacks $(9.7 \%)$ than whites $(5.5 \%)$. White individuals had higher rates of cesarean delivery $(34.9 \%)$. Skin color remained as an independent risk factor for low birth weight $(\mathrm{P}<0.001)$, preterm birth $(\mathrm{P}=0.01)$, small for gestational age $(P=0.01)$, and lack of prenatal care $(P=0.02)$ after adjustment for family income and maternal schooling, suggesting that the racial inequalities regarding these indicators are explained by the socioeconomic disadvantage experienced by mulattos and blacks but are also influenced by other factors, possibly by racial discrimination and/or genetics.
\end{abstract}

Key words

- Ethnic-racial discrimination

- Prenatal care

- Preterm birth

- Low birth weight

- Perinatal health

- Cesarean section

\section{Introduction}

Natives, mulattos, blacks, and whites occupy unequal places in the social networks, with differential aspects related to birth, growth, disease, and dying. Racial inequality is not limited to socioeconomic indicators related to quality of life, income and school- ing but also occurs in health indicators. In the United States, which have a tradition of research on racial questions, the rates of preterm birth, low birth weight and infant mortality are higher among blacks than among whites $(1,2)$.

Although Brazil is considered to be a country in which racial discrimination is not 
so significant and in which "racial democracy" prevails, significant socioeconomic inequalities related to diverse ethnic groups exist in this country $(3,4)$. Even in cities in the south of the country, where there is better access to health services, black women have fewer opportunities to receive ideal prenatal care, with repercussions on perinatal health (5-7). In the town of Pelotas, black children have a higher prevalence of low birth weight, preterm birth and restricted intrauterine growth (8). In a study conducted in Rio de Janeiro, black mothers had lower schooling, a greater proportion of smokers and lower prenatal care attendance, cohabited less, and had a higher prevalence of pregnancy during adolescence (9). In Brazil in general, infant mortality is higher among blacks and native Indians (10).

The race/ethnic group category is not useful as a biological category, but is a social construct $(11,12)$. In Brazil, the term race is normally used to refer to phenotype (physical appearance) rather than to ancestrality (origin), as is the case in the US. While US research is based on categories of "pure" races, in Brazil the "brown" or "mulatto" category is commonly used also to refer to cross-bred individuals (13). The determination of race in health studies is usually done by the interviewer, whereas the more recommended procedure is self-classification (11).

Few studies regarding ethnic inequalities and perinatal health have been conducted in Brazil, mainly due to low availability and/or quality of the data or to inadequate instruments for the measurement of race/ethnic origin. Questions related to the inequalities existing between individuals of mulatto and black skin colors have not been fully clarified, with these groups being usually analyzed as non-white in relation to whites. It has not been clarified whether the inequalities existing between ethnic groups regarding perinatal factors are due to socioeconomic factors or to other cultural or genetic factors. To clarify these questions, a study was conducted to analyze a cohort of individuals born in Ribeirão Preto, SP, in which skin color self-reported in adulthood in 2002/ 2004 was related to the social, economic, obstetrical, and perinatal characteristics of the subjects at birth in 1978/79.

\section{Material and Methods}

The data used in the present study originate from a cohort from the city of Ribeirão Preto, SP, comprising births during the period from June 1st, 1978 to May 31st, 1979. Data referring to 9067 births were obtained during that period, representing approximately $98 \%$ of the liveborn infants delivered at the eight maternities of Ribeirão Preto hospitals. Of these births, 6973 were from mothers residing in the municipality itself. The information was obtained by interviewing the mothers and from the medical records of the maternity hospitals $(14,15)$.

A search for the individuals initially included in the cohort, currently ranging in age from 23 to 25 years, was started in 2002 and continued through 2004. The search was based on sources such as the electronic registry of patients covered by the Unified Health System of Ribeirão Preto (scheduling of visits by the Hygia System), cards for the evaluation of schoolchildren from the cohort performed in 1987-89, lists of users containing the mother's name and address, data from the private health plans, and data obtained at the time of recruitment for military service. A total of 2063 young adults effectively participated in the study after giving free informed consent, corresponding to $31.8 \%$ of the original sample, after exclusion of 146 twin births and 343 deaths up to 20 years of age. During the interview, skin color was self-reported, with the subject choosing one of the following closed alternatives in response to the question: "What is your skin color?": mulatto (brown), black, white, yellow, and native, according to the standards used by the Brazilian Institute of Geography 
and Statistics (IBGE) $(13,16)$.

In the present study, individuals of yellow color or natives were included in the group of subjects with mulatto skin color, a criterion used because of the small number of individuals belonging to these categories.

The partitioning chi-square test was used for the categorical variables, with the $\mathrm{P}$ values referring to the comparison between black and mulatto individuals or between whites and non-whites (mulatto and black individuals), and with the level of significance set at $\mathrm{P}<0.05$. Logistic regression was used in order to control the possible confounding effect of family income and maternal schooling on the evaluation of race/ethnic group inequalities in relation to the following perinatal factors: low birth weight, small for gestational age birth, preterm birth, lack of prenatal care, and type of delivery. Infants whose weight was below the 10th percentile for gestational age were considered to be small for gestational age (17). Cases whose birth weight was incompatible with the last normal menstrual period or whose gestational age was implausible were recorded as missing. Missing data on gestational age comprised $25 \%$. All cases with missing gestational age were imputed in a linear regression model (18). Characteristics used to impute gestational age were birth weight, parity, family income, and newborn gender.

\section{Results}

The study was conducted on 2063 persons, 1367 of them $(66.3 \%)$ white, 603 (29.2\%) mulatto and 93 (4.5\%) black. Mulatto and black individuals were born to younger fathers $(\mathrm{P}=0.068)$ and mothers $(\mathrm{P}$ $<0.001)$ than white individuals. Mulatto and black individuals were born to a higher percentage of cohabiting mothers or mothers with no companion at the time of giving birth $(\mathrm{P}<0.001)$. The mothers of mulatto individuals $(28.8 \%)$ smoked more during pregnancy than the mothers of blacks $(24.1 \%)$ and whites $(22.5 \%)$, with a statistically significant difference between whites and other ethnic groups $(P=0.006)$. Paternal smoking habit was less frequent among whites (54.8\%), with a significant difference between them and the other ethnic groups $(\mathrm{P}=$ 0.035; Table 1).

The mothers of white individuals had a higher percentage of family income of more than three minimum wages $(54.4 \%)$ than the mothers of mulatto $(30.2 \%)$ and black $(25.3 \%)$ individuals $(\mathrm{P}<0.001)$. The percentage of mothers working outside the home was higher among mothers of mulatto individuals $(83.1 \%)$. There was no significant difference between mulatto and black subjects regarding family income and maternal work outside the home at the time of their birth. The occupation of the head of the family belonging to the unskilled and unemployed categories was significantly higher $(\mathrm{P}=0.003)$ among black $(39.3 \%)$ than mulatto $(26.7 \%)$ individuals. The heads of the

Table 1. Demographic factors, marital status and parental smoking habit at birth according to self-reported skin color in adult life, Ribeirão Preto, 1978/79.

\begin{tabular}{lccc}
\hline Variables & \multicolumn{3}{c}{ Skin color } \\
\cline { 2 - 4 } & Mulatto & Black & White \\
\hline Maternal age (years) & & & \\
$\quad<20$ & $104(17.0 \%)$ & $13(14.0 \%)$ & $137(10.1 \%)$ \\
20 to 34 & $436(72.9 \%)$ & $69(74.2 \%)$ & $1121(82.4 \%)^{*}$ \\
$\geq 35$ & $58(9.7 \%)$ & $11(11.8 \%)$ & $102(7.5 \%)$ \\
$\begin{array}{l}\text { Paternal age (years) } \\
<20\end{array}$ & $17(3.1 \%)$ & $3(3.5 \%)$ & $16(1.2 \%)$ \\
20 to 34 & $423(76.1 \%)$ & $64(73.5 \%)$ & $993(76.5 \%)^{*}$ \\
$\geq 35$ & $116(20.8 \%)$ & $20(23.0 \%)$ & $289(22.3 \%)$ \\
Marital status & & & \\
$\quad$ No companion & $44(7.5 \%)$ & $10(10.8 \%)$ & $51(3.8 \%)$ \\
$\quad$ Married & $495(82.9 \%)$ & $69(74.2 \%)$ & $1246(91.8 \%)^{*}$ \\
$\quad$ Cohabiting & $58(9.6 \%)$ & $14(15.0 \%)$ & $60(4.4 \%)^{*}$ \\
Maternal smoking & & & \\
Yes & $160(28.8 \%)$ & $21(24.1 \%)$ & $292(22.5 \%)$ \\
$\quad$ No & $396(71.2 \%)$ & $66(75.9 \%)$ & $1006(77.5 \%)^{*}$ \\
Paternal smoking & $332(59.7 \%)$ & $53(60.9 \%)$ & $712(54.8 \%)$ \\
$\quad$ Yes & $224(40.3 \%)$ & $34(39.1 \%)$ & $586(45.2 \%)^{*}$ \\
$\quad$ No &
\end{tabular}

Data are reported as number with percent in parentheses. Totals differ because of missing values.

${ }^{*} P<0.05$, Whites vs non-Whites (chi-square partitioning test). 
family of white individuals had higher percentages of non-manual occupations $(22.3 \%)$ (Table 2).

The mothers of white individuals had a $14.4 \%$ rate of more than 12 years of schooling compared to $3.6 \%$ for the mothers of mulatto individuals and $1.1 \%$ for the mothers of black individuals $(\mathrm{P}<0.001)$. There was a statistically significant difference between the mothers of mulatto individuals and the mothers of black individuals in the category of four years of schooling or less $(\mathrm{P}$ $=0.01$ ), with the mothers of blacks presenting higher percentages $(38.0 \%)$ of low schooling. The percentage of maternal illiteracy was significantly higher among blacks

Table 2. Socioeconomic factors at birth according to self-reported skin color in adult age, Ribeirão Preto, 1978/79.

\begin{tabular}{|c|c|c|c|}
\hline \multirow[t]{2}{*}{ Socieconomic factors } & \multicolumn{3}{|c|}{ Skin color } \\
\hline & Mulatto & Black & White \\
\hline \multicolumn{4}{|c|}{ Family income (minimum wages) } \\
\hline$>3$ & $148(30.2 \%)$ & $20(25.3 \%)$ & $611(54.4 \%)$ \\
\hline More than 1 and up to 3 & $202(41.2 \%)$ & $35(44.3 \%)$ & $367(32.7 \%)^{+}$ \\
\hline$\leq 1$ & $140(28.6 \%)$ & $24(30.4 \%)$ & $145(12.9 \%)^{+}$ \\
\hline \multicolumn{4}{|c|}{ Mother working outside the home } \\
\hline Yes & $492(83.1 \%)$ & $69(75.0 \%)$ & $1049(78.2 \%)$ \\
\hline No & $100(16.9 \%)$ & $23(25.0 \%)$ & $292(21.8 \%)^{+}$ \\
\hline \multicolumn{4}{|c|}{ Occupation of the head of the family } \\
\hline Non-manual & 45 (7.9\%) & $3(3.4 \%)$ & 291 (22.3\%) \\
\hline Skilled and semiskilled & $371(65.4 \%)$ & $51(57.3 \%)$ & $842(64.6 \%)^{+}$ \\
\hline Unskilled/unemployed & $151(26.7 \%)$ & $35(39.3 \%)^{*}$ & $171(13.1 \%)^{+}$ \\
\hline \multicolumn{4}{|l|}{ Maternal schooling (years) } \\
\hline$\geq 12$ & $21(3.6 \%)$ & $1(1.1 \%)$ & $193(14.4 \%)$ \\
\hline 5 to 11 & $408(69.2 \%)$ & $56(60.9 \%)$ & $959(71.5 \%)^{+}$ \\
\hline$\leq 4$ & $161(27.2 \%)$ & $35(38.0 \%)^{*}$ & $189(14.1 \%)^{+}$ \\
\hline \multicolumn{4}{|l|}{ Paternal schooling (years) } \\
\hline$\geq 12$ & $21(4.1 \%)$ & $0(0.0 \%)$ & $244(19.7 \%)$ \\
\hline 5 to 11 & $170(33.2 \%)$ & $22(29.3 \%)$ & $539(43.6 \%)^{+}$ \\
\hline$\leq 4$ & $321(62.7 \%)$ & $53(70.7 \%)$ & $454(36.7 \%)^{+}$ \\
\hline \multicolumn{4}{|l|}{ Maternal illiteracy } \\
\hline Yes & $26(4.4 \%)$ & $11(12.0 \%)$ & $20(1.5 \%)$ \\
\hline No & $566(95.6 \%)$ & $81(88.0 \%)^{*}$ & $1321(98.5 \%)^{+}$ \\
\hline \multicolumn{4}{|l|}{ Paternal illiteracy } \\
\hline Yes & $28(5.5 \%)$ & $1(1.3 \%)$ & 17 (1.4\%) \\
\hline No & $484(94.5 \%)$ & $74(98.7 \%)^{*}$ & $1220(98.6 \%)^{+}$ \\
\hline
\end{tabular}

Data are reported as number with percent in parentheses. Totals differ because of missing values.

${ }^{*} \mathrm{P}<0.05$, Mulattos vs Blacks; ${ }^{+} \mathrm{P}<0.05$, Whites vs non-Whites (chi-square partitioning test).
(12.0\%), with significant differences between the three ethnic groups $(\mathrm{P}<0.001)$. Paternal schooling of more than 12 years was also higher among whites $(19.7 \%)$ than among mulatto $(4.1 \%)$ and black $(0.0 \%)$ individuals and the percentage of paternal illiteracy was higher among mulatto individuals (Table 2).

The low birth weight rate was significantly higher for mulatto individuals $(9.6 \%)$ compared to blacks $(4.3 \%)$ and whites $(4.8 \%)$ $(\mathrm{P}=0.001)$. The percentage of small for gestational age babies was higher among mulatto individuals (12.8\%), with no difference between them and blacks $(\mathrm{P}=0.11)$. The preterm birth rate was lower among whites $(5.5 \%)$ than among mulatto (9.5\%), and black $(9.7 \%)$ individuals, with no difference between the last two groups $(\mathrm{P}=0.93$; Table 3).

The percentage of mothers of black individuals receiving prenatal care $(86.0 \%)$ was lower than the percentage of mothers of mulatto $(91.1 \%)$, and white $(96.9 \%)$ individuals, with the difference being statistically significant $(P=0.001)$. Prenatal care provided by public services was more frequent among the mothers of blacks $(93.7 \%)$. A higher percentage of cesarean sections was observed among the mothers of whites (34.9\%) (Table 3).

After adjusting for family income and maternal schooling, mulatto skin color remained independently associated with low birth weight, being small for gestational age and preterm birth. Mulatto and black colors were independent risk factors for the lack of prenatal care. Mothers of mulatto and black individuals had a lower risk to deliver by cesarean section (Table 4).

\section{Discussion}

Blacks presented more unfavorable socioeconomic indicators than whites. Mulatto individuals had a more favorable socioeconomic situation than blacks, but more unfavorable than that of whites. Mulatto and 
black individuals presented more unfavorable indicators of perinatal health than whites. Even after adjusting for income of the head of the family and maternal schooling, individuals of mulatto or black color presented higher risks of low birth weight, preterm birth, being small for gestational age, and lack of prenatal care.

Individuals of black and mulatto colors presented an evident disadvantage compared to whites, confirming previous studies showing that the mothers of blacks study less, have a lower income and greater parity, smoke more, and receive less prenatal care, with all of these factors influencing perinatal health (7).

Black and mulatto women presented higher percentages of pregnancy during adolescence than white women, in agreement with data reported by Perpétuo (19). Black and mulatto women presented higher percentages of cohabiting and of absence of a companion, suggesting that unplanned pregnancy is more frequent among these groups as a reflex of different types of social exclusion such as less use of contraceptives, lower schooling and less access to information (19, 20). Olinto and Olinto (5) observed that black women use contraceptives less than white women do.

In 2001 , the rate of illiteracy was $12.4 \%$ among Brazilians aged 15 years or more, being $18.2 \%$ for blacks and $7.7 \%$ for whites. On average, the white population studied for 6.9 years and the black population studied for 4.7 years $(4,21)$. In the present study, the rates of maternal illiteracy were significantly higher for blacks $(12.0 \%)$ than for whites $(1.5 \%)$.

The percentage of mothers working outside the home was more expressive among mulatto women, whereas black women presented lower indices. In addition to being discriminated against because of their skin color, black women are also the victims of prejudice regarding gender, being more penalized in their attempt to enter the work market and to obtain just remuneration (4, 22,23). According to Soares (22), if there were an end to racial discrimination, black women would earn, on average, $60 \%$ more and black men 10 to $25 \%$ more than whites.

Maternal smoking habit during pregnancy was significantly higher among mulatto and black women, with negative consequences for the health of the newborns, such as low birth weight (24). Leal et al. (9) observed that, when the pregnant women were stratified according to schooling level and income, the smoking habit was found to be more prevalent among black and mulatto women of lower schooling and income.

The low birth weight rate was lower

Table 3. Perinatal factors according to self-reported skin color in adult age, Ribeirão Preto, 1978/79.

\begin{tabular}{|c|c|c|c|}
\hline \multirow[t]{2}{*}{ Perinatal factors } & \multicolumn{3}{|c|}{ Skin color } \\
\hline & Mulatto & Black & White \\
\hline \multicolumn{4}{|l|}{ Low birth weight } \\
\hline Yes & $58(9.6 \%)$ & $4(4.3 \%)$ & $66(4.8 \%)$ \\
\hline No & $545(90.4 \%)$ & $89(95.7 \%)^{*}$ & $1301(95.2 \%)^{+}$ \\
\hline \multicolumn{4}{|c|}{ Weight for gestational age } \\
\hline SGA & $77(12.8 \%)$ & $7(7.5 \%)$ & $119(8.7 \%)$ \\
\hline AGA & $501(83.0 \%)$ & $82(88.2 \%)$ & $1153(84.3 \%)^{+}$ \\
\hline LGA & $25(4.2 \%)$ & $4(4.3 \%)$ & $95(7.0 \%)^{+}$ \\
\hline \multicolumn{4}{|l|}{ Preterm birth } \\
\hline Yes & 57 (9.5\%) & $9(9.7 \%)$ & $75(5.5 \%)$ \\
\hline No & $546(90.5 \%)$ & $84(90.3 \%)$ & $1292(94.5 \%)^{+}$ \\
\hline \multicolumn{4}{|l|}{ Parity } \\
\hline 1 & $224(37.2 \%)$ & $30(32.3 \%)$ & $519(37.9 \%)$ \\
\hline 2 to 4 & $302(50.1 \%)$ & $47(50.5 \%)$ & $729(53.4 \%)$ \\
\hline$\geq 5$ & 77 (12.7\%) & $16(17.2 \%)$ & $119(8.7 \%)^{+}$ \\
\hline \multicolumn{4}{|l|}{ Prenatal care } \\
\hline Yes & $482(91.1 \%)$ & $74(86.0 \%)$ & $1117(96.9 \%)$ \\
\hline No & $47(8.9 \%)$ & $12(14.0 \%)$ & $38(3.1 \%)^{+}$ \\
\hline \multicolumn{4}{|c|}{ Prenatal care category } \\
\hline Health plan & $46(8.5 \%)$ & $2(2.5 \%)$ & $172(13.3 \%)$ \\
\hline Private & $17(3.2 \%)$ & $3(3.8 \%)$ & $152(11.8 \%)^{+}$ \\
\hline Public & 475 (88.3\%) & $74(93.7 \%)$ & $969(74.9 \%)^{+}$ \\
\hline \multicolumn{4}{|l|}{ Type of delivery } \\
\hline Vaginal & 439 (72.8\%) & $73(78.5 \%)$ & $890(65.1 \%)$ \\
\hline Cesarean section & $164(27.2 \%)$ & $20(21.5 \%)$ & $477(34.9 \%)^{+}$ \\
\hline
\end{tabular}

Data are reported as number with percent in parentheses. SGA = small for gestational age; $A G A=$ adequate for gestational age; $L G A=$ large for gestational age. Totals for some variables may differ because of missing values.

${ }^{*} \mathrm{P}<0.05$, Mulattos vs Blacks; ${ }^{+} \mathrm{P}<0.05$, Whites vs non-Whites (chi-square partitioning test). 
Table 4. Crude and adjusted risks of low birth weight, preterm birth, small for gestational age birth, no prenatal care, and type of delivery according to self-reported skin color in adult age, Ribeirão Preto, 1978/79.

\begin{tabular}{lcc}
\hline Factors & $\begin{array}{c}\text { Non-adjusted OR } \\
(95 \% \mathrm{Cl})\end{array}$ & $\begin{array}{c}\text { Adjusted OR } \\
(95 \% \mathrm{Cl})\end{array}$ \\
\hline
\end{tabular}

Low birth weight

Skin color

White

Mulatto

Black

Family income (minimum wages)

$>3$

More than 1 and up to 3

$\leq 1$

Maternal schooling (years)

$\geq 12$

5 to 11

$\leq 4$

Small for gestational age birth

Skin color

White

Mulatto

Black

Family income (minimum wages)

$>3$

More than 1 and up to 3

$\leq 1$

Maternal schooling (years)

$\geq 12$

5 to 11

$\leq 4$

Preterm birth

Skin color

White

Mulatto

Black

Family income (minimum wages)

$>3$

More than 1 and up to 3

$\leq 1$

Maternal schooling (years)

$\geq 12$

5 to 11

$\leq 4$

No prenatal care

Skin color

White

Mulatto

Black

Family income (minimum wages)

$>3$

More than 1 and up to 3

$\leq 1$

Maternal schooling (years)

$\geq 5^{\#}$

$\leq 4$
$1.00 \quad 1.00$

$2.09(1.45-3.02)$

$0.88(0.31-2.48)^{*}$

$2.15(1.41-3.28)$

$0.74(0.22-2.45)^{*}$

1.00

1.00

$2.17(1.33-3.54)$

$1.80(1.00-3.24)^{*}$

NS

1.00

$2.36(1.34-10.14)$

$2.15(1.37-11.52)^{\star}$

\subsection{0}

1.00

$1.53(1.13-2.08)$

$0.85(0.38-1.88)^{\star}$

$1.63(1.18-2.32)$

$0.77(0.32-1.85)^{*}$

1.00

$1.85(1.27-2.68)$

$2.21(1.44-3.39)^{\star}$

1.00

$1.55(0.87-2.74)$

2.04 (1.09-3.80)

\subsection{0}

$1.79(1.25-2.57)$

$1.84(0.89-3.81)^{\star}$

1.00

$2.05(1.35-3.12)$

$1.38(0.80-2.39)^{\star}$

1.00

$1.82(0.90-3.65)$

$1.52(0.69-3.33)$

1.00

$3.02(1.94-4.69)$

$5.02(2.51-10.01)^{\star}$

1.00

$3.89(1.72-8.77)$

$12.67(5.79-27.7)^{\star}$

$3.37(1.48-7.65)$

1.00

$3.58(2.35-5.46)^{\star}$
$3.47(1.51-7.95)^{*}$

$10.00(4.48-22.34)^{*}$
1.00

$1.82(1.04-3.18)$

1.00

NS

$1.76(0.80-3.86)$

1.00

$(1.22-2.59)$

$1.14(0.65-2.01)^{*}$

NS

Continued on next page among white than among mulatto and black mothers. Some studies have reported that racial differences regarding low birth weight persist even when socioeconomic factors are considered, suggesting a possible genetic explanation for this difference (25). However, David and Collins (26), comparing American and African immigrant black mothers in the United States, observed that black African mothers with better socioeconomic conditions had lower rates of low birth weight infants than American black mothers and concluded that the racial question was not a determinant explaining low birth weight, which was much more affected by the socioeconomic and cultural conditions of the mother. However, in the present study skin color remained as an independent risk factor for low birth weight when the data were adjusted for income and maternal schooling, a fact clearly showing that socioeconomic factors are not the only ones explaining the inequalities in low birth weight in relation to ethnic group. The stress associated with the experience of situations of racial discrimination may be a factor explaining these inequalities (27).

In the present study, the low birth weight rate was lower among blacks than among mulatto and white individuals, a fact that may be explained by selection bias since blacks whose socioeconomic conditions were more unfavorable had higher mortality rates and probably had lower percentages of follow-up in this cohort study. Since ethnic group was self-reported during adulthood, information for ethnic group was available only for individuals followed up until adulthood. Since follow-up rates were lower for less economically privileged groups, and the social indicators were more unfavorable for blacks, this may have caused an underestimate of low birth weight in this group. The higher rate of low birth weight among mulatto individuals may be related among other factors to the higher prevalence of smoking during pregnancy among women of mulatto 
color.

Higher percentages of preterm and small for gestational age babies were observed among persons of black and mulatto skin colors, in agreement with data reported by Barros et al. (8). This may reflect the more unfavorable social situation of these groups $(4,19)$ and may also be associated with erroneous determination of the date of last normal menstrual period, more common among women with a lower educational level, causing an overestimate of preterm birth rates (8). In the present study, even after controlling for income and schooling, higher risks of preterm and small for gestational age babies remained for these groups, showing that the ethnic-racial inequalities regarding these indicators of perinatal health are not simply due to social disadvantage $(28,29)$. This demystifies the idea of "racial democracy" in Brazil and the notion that ethnic inequalities in perinatal health in Brazil are simply due to socioeconomic inequalities.

Barros et al. (8) in the town of Pelotas, southern Brazil, observed poor quality of prenatal care provided to black women. Leal et al. (9) reported that ethnic inequalities occur both in terms of access to and quality of prenatal care: black women have a more difficult access to prenatal care and, when they receive it, it is of poorer quality, in agreement with the data of the present study, in which black and mulatto women had more infrequent prenatal care. In the present study, black and mulatto skin colors were risk factors for lack of prenatal care not depending on income or schooling, suggesting that, in addition to the economic and educational question, inequality also seems to be influenced by the experience of racial discrimination. The lack of prenatal care was also

\begin{tabular}{|c|c|c|}
\hline Factors & $\begin{array}{c}\text { Non-adjusted OR } \\
(95 \% \mathrm{Cl})\end{array}$ & $\begin{array}{l}\text { Adjusted OR } \\
(95 \%) \mathrm{Cl})\end{array}$ \\
\hline \multicolumn{3}{|l|}{ Cesarean section } \\
\hline \multicolumn{3}{|l|}{ Skin color } \\
\hline White & 1.00 & 1.00 \\
\hline Mulatto & $0.69(0.56-0.86)$ & $0.75(0.59-0.96)$ \\
\hline Black & $0.51(0.30-0.84)^{*}$ & $0.61(0.35-1.07)^{*}$ \\
\hline Family income (minimum wages) & & NS \\
\hline$>3$ & $1.47(1.17-1.85)$ & \\
\hline More than 1 and up to 3 & 1.00 & \\
\hline$\leq 1$ & $0.78(0.57-1.07)^{\star}$ & \\
\hline \multicolumn{3}{|l|}{ Maternal schooling (years) } \\
\hline$\geq 12$ & $1.65(1.23-2.21)$ & $1.43(1.05-1.96)$ \\
\hline 5 to 11 & 1.00 & 1.00 \\
\hline$\leq 4$ & $0.55(0.42-0.72)^{\star}$ & $0.54(0.39-0.73)^{*}$ \\
\hline
\end{tabular}

$\mathrm{OR}=$ odds ratio; $\mathrm{Cl}=$ confidence interval; $\mathrm{NS}=$ non-significant. \#Due to the small number of mothers with $\geq 12$ years of schooling who did not attend prenatal care, this category was joined with 5-11 years of schooling.

${ }^{*} \mathrm{P}<0.05$ (chi-square test).

associated with skin color in the study by Barros et al. (8) even after adjustment for schooling level and income. The fact that women of mulatto skin color predominantly have vaginal deliveries reflects a lower access to this medical technology, but may also be considered to be a positive indicator because of the lower risk of unnecessary cesarean deliveries to which this group is exposed.

The racial self-classification of the individuals when adult permitted a more reliable measurement of ethnic group in this cohort study. The present study had some limitations. Ethnic group was self-reported during adulthood, thus information for ethnic group was available only for individuals followed up until adulthood. Since follow-up was not complete, losses were greater in the less privileged socioeconomic groups, a fact that may have underestimated racial inequalities.

\section{References}

1. Demissie K, Rhoads GG, Ananth CV, Alexander GR, Kramer MS, Kogan MD, et al. Trends in preterm birth and neonatal mortality among blacks and whites in the United States from 1989 to 1997. Am J Epidemiol 2001; 154: 307-315. 
2. Pallotto EK, Collins JW Jr, David RJ. Enigma of maternal race and infant birth weight: a population-based study of US-born Black and Caribbean-born Black women. Am J Epidemiol 2000; 151: 10801085.

3. Oliveira CLP, Barreto PCS. Perception of racism in Rio de Janeiro. Estud Afro-Asiát 2003; 25: 183-213.

4. Lopes F. Experiências desiguais ao nascer, viver, adoecer, e morrer: tópicos em saúde da população negra no Brasil. Seminário Nacional de Saúde da População Negra - Cadernos de textos básicos. Ministério da Saúde. Brasília: 2004.

5. Olinto MTA, Olinto BA. Raça e desigualdade entre as mulheres: um exemplo no sul do Brasil. Cad Saúde Pública 2000; 16: 1137-1142.

6. Cunha EMGP, Jakobo AAE. Diferenças raciais nos perfis e estimativas de mortalidade infantil para o Brasil. In: Lopes F (Editor), Saúde da população negra no Brasil: contribuições para promoção da equidade. Brasília: Funasa; 2004.

7. Oliveira F. Ser negro no Brasil: alcances e limites. Estud Av 2004; 18: $57-60$.

8. Barros FC, Victora CG, Horta BL. Ethnicity and infant health in Southern Brazil. A birth cohort study. Int J Epidemiol 2001; 30: 10011008.

9. Leal MC, Gama SGN, Cunha BC. Desigualdades raciais, sociodemográficas e na assistência ao pré-natal e ao parto, 1999-2001. Rev Saúde Pública 2005; 39: 100-107.

10. Cardoso AM, Santos RV, Coimbra CE Jr. Infant mortality according to race/color in Brazil: what do the national databases say? Cad Saúde Pública 2005; 21: 1602-1608.

11. Chor D, Lima CR. Epidemiologic aspects of racial inequalities in health in Brazil. Cad Saúde Pública 2005; 21: 1586-1594.

12. Chaturvedi N. Ethnicity as an epidemiological determinant - crudely racist or crucially important? Int J Epidemiol 2001; 30: 925-927.

13. Travassos C, Williams DR. The concept and measurement of race and their relationship to public health: a review focused on Brazil and the United States. Cad Saúde Pública 2004; 20: 660-678.

14. Barbieri MA, Gomes UA, Barros-Filho AA, Bettiol H, Almeida LEA Silva AAM. Saúde perinatal em Ribeirão Preto, SP, Brasil: a questão do método. Cad Saúde Pública 1989; 5: 376-387.

15. Cardoso VC, Simões VMF, Barbieri MA, Silva AAM, Bettiol H, Alves MTSSB, et al. Profile of three Brazilian birth cohort studies in Ribeirão Preto, SP and São Luís, MA. Braz J Med Biol Res 2007; 1165-1176.
16. Barbieri MA, Bettiol H, Silva AA, Cardoso VC, Simoes VM, Gutierrez MR, et al. Health in early adulthood: the contribution of the 1978/79 Ribeirão Preto birth cohort. Braz J Med Biol Res 2006; 39: 1041 1055.

17. Williams RL, Creasy RK, Cunningham GC, Hawes WE, Norris FD, Tashiro M. Fetal growth and perinatal viability in California. Obstet Gynecol 1982; 59: 624-632.

18. Rubin DB. Multiple imputation for nonresponse in surveys. New York: John Wiley \& Sons; 1987.

19. Perpétuo IHO. Raça e acesso às ações prioritárias na agenda da saúde reprodutiva. J Rede Fem Saúde 2000; 22: 10-16.

20. Pinto E, Souza R. A mortalidade materna e a questão raça/etnia: importância da lei do quesito cor no sistema de saúde. Perspect Saúde Direitos Reprod 2002; 5: 28-30.

21. IBGE - Fundação Instituto Brasileiro de Geografia e Estatística. Indicadores sociais mínimos censo 2000. http://www.ibge.gov.br/ população/condicaodevida/indicadores. Accessed December 14, 2004.

22. Soares S. Discriminação de gênero e raça no mercado de trabalho. Mercado de trabalho: conjuntura e análise. Edição especial para a Conferência Nacional contra o Racismo e a Intolerância. Rio de Janeiro: IPEA; 2001.

23. Campante FR, Crespo ARV, Leite PGPG. Desigualdade salarial entre raças no mercado de trabalho urbano brasileiro: aspectos regionais. Rev Bras Econ 2004; 58: 185-210.

24. Kogan MD, Kotelchuck M, Alexander GR, Johnson WE. Racial disparities in reported prenatal care advice from health care providers. Am J Public Health 1994; 84: 82-88.

25. Sheehan TJ, Gregorio DI. Low birth weight in relation to the interval between pregnancies. N Engl J Med 1995; 333: 386-387.

26. David RJ, Collins JW Jr. Differing birth weight among infants of U.S.born blacks, African-born blacks, and U.S.-born whites. $N$ Engl $J$ Med 1997; 337: 1209-1214.

27. Sheehan TJ. Stress and low birth weight: a structural modeling approach using real life stressors. Soc Sci Med 1998; 47: 15031512.

28. Nazroo JY. The structuring of ethnic inequalities in health: economic position, racial discrimination and racism. Am J Publ Health 2003; 93: 277-284.

29. Pearce NP, Foliaki S, Sporle A, Cunningham C. Genetics, race, ethnicity and health. BMJ 2004; 328: 1070-1072. 